\title{
A Dynamic Link between Ice Nucleating Particles Released in Nascent Sea Spray Aerosol and Oceanic Biological Activity during Two Mesocosm Experiments ${ }^{\mathscr{O}}$
}

\author{
Christina S. McCluskey, ${ }^{\mathrm{a}}$ Thomas C. J. Hill, ${ }^{\mathrm{a}}$ Francesca Malfatti, ${ }^{\mathrm{b}}{ }^{\mathrm{C}}$ CAmille M. Sultana, \\ Christopher LeE, ${ }^{\mathrm{c}}$ Mitchell V. SANTANDER, ${ }^{\mathrm{c}}$ CHARlotTe M. Beall, ${ }^{\mathrm{c}}$ Kathryn A. Moore, ${ }^{\mathrm{c}}$ \\ Gavin C. Cornwell, ${ }^{\mathrm{c}}$ Douglas B. Collins,${ }^{\mathrm{c}}{ }^{\mathrm{c}}$ Kimberly A. Prather,${ }^{\mathrm{c}}$ Thilina Jayarathne, ${ }^{\mathrm{d}}$ \\ Elizabeth A. Stone, ${ }^{d}$ Faroog Azam, ${ }^{\mathrm{c}, \mathrm{e}}$ Sonia M. Kreidenweis, ${ }^{\mathrm{a}}$ And Paul J. DeMotT ${ }^{\mathrm{a}}$ \\ ${ }^{\text {a } C o l o r a d o ~ S t a t e ~ U n i v e r s i t y, ~ F o r t ~ C o l l i n s, ~ C o l o r a d o ~}$ \\ ${ }^{\mathrm{b}}$ Istituto Nazionale di Oceanografia e di Geofisica Sperimentale, Trieste, Italy \\ ${ }^{\mathrm{c}}$ University of California, San Diego, La Jolla, California \\ ${ }^{\mathrm{d}}$ The University of Iowa, Iowa City, Iowa \\ ${ }^{\text {e }}$ Scripps Institution of Oceanography, La Jolla, California
}

(Manuscript received 13 March 2016, in final form 15 August 2016)

\begin{abstract}
Emission rates and properties of ice nucleating particles (INPs) are required for proper representation of aerosol-cloud interactions in atmospheric models. Few investigations have quantified marine INP emissions, a potentially important INP source for remote oceanic regions. Previous studies have suggested INPs in sea spray aerosol (SSA) are linked to oceanic biological activity. This proposed link was explored in this study by measuring INP emissions from nascent SSA during phytoplankton blooms during two mesocosm experiments. In a Marine Aerosol Reference Tank (MART) experiment, a phytoplankton bloom was produced with chlorophyll-a (Chl a) concentrations reaching $39 \mu \mathrm{g} \mathrm{L}^{-1}$, while $\mathrm{Chl}$ a concentrations more representative of natural ocean conditions were obtained during the Investigation into Marine Particle Chemistry and Transfer Science (IMPACTS; peak $\mathrm{Chl}$ a of $5 \mu \mathrm{g} \mathrm{L}^{-1}$ ) campaign, conducted in the University of California, San Diego, wave flume. Dynamic trends in INP emissions occurred for INPs active at temperatures $>-30^{\circ} \mathrm{C}$. Increases in INPs active between $-25^{\circ}$ and $-15^{\circ} \mathrm{C}$ lagged the peak in $\mathrm{Chl}$ a in both studies, suggesting a consistent population of INPs associated with the collapse of phytoplankton blooms. Trends in INP emissions were also compared to aerosol composition, abundances of microbes, and enzyme activity. In general, increases in INP concentrations corresponded to increases in organic species in SSA and the emissions of heterotrophic bacteria, suggesting that both microbes and biomolecules contribute to marine INP populations. INP trends were not directly correlated with a single biological marker in either study. Direct measurements of INP chemistry are needed to accurately identify particles types contributing to marine INP populations.
\end{abstract}

\section{Introduction}

Understanding the formation, dynamics, precipitation rates, and lifetimes of mixed-phase clouds, which contain both supercooled liquid droplets and ice crystals, is complicated by uncertainties in representation of aerosol-cloud interactions. Heterogeneous ice nucleation is a key process in mixed-phase clouds, where supercooled droplets are

Supplemental information related to this paper is available at the Journals Online website: http://dx.doi.org/10.1175/ JAS-D-16-0087.s1.

Corresponding author e-mail: Christina McCluskey, mccluscs@ atmos.colostate.edu nucleated into ice crystals by ice nucleating particles (INPs). Although their presence in the atmosphere is rare [e.g., 1 INP for every $1 \times 10^{5}$ aerosol particles (Rogers et al. 1998)], INPs can quickly transform a liquid-dominated cloud into an ice-dominated cloud via the WegenerBergeron-Findeisen process (Pruppacher and Klett 1997; Korolev 2007), thereby modifying the cloud's precipitation rates, lifetime, and radiative properties. Numerical representation of ice processes in clouds remains poorly constrained in global climate models, as demonstrated by McCoy et al. (2015), who revealed that the glaciation temperature (i.e., temperature at which equal amounts of liquid and ice condensate are present in a cloud) in 19 different global climate models ranged widely, from $-38^{\circ}$ to $-3^{\circ} \mathrm{C}$. The representation of ice in mixed-phase clouds 
is dependent on several parameters, including ice growth, precipitation microphysics, and cloud droplet size distributions (Komurcu et al. 2014), as well as the abundance of INPs (e.g., DeMott et al. 2010). To accurately represent spatial and temporal distributions of available INPs, much work remains to be done to understand the abundance and characteristics of INPs associated with various aerosol types.

Observational studies of ambient INPs have been made in both coastal and oceanic regions (e.g., Bigg 1973; Schnell and Vali 1976; Rosinski et al.1987; Bigg 1996; Prenni et al. 2009; DeMott et al. 2015). The first survey of oceanic INPs reported atmospheric concentrations of INPs active at $-15^{\circ} \mathrm{C}$ in the immersion freezing nucleation mode [where an INP is immersed in a droplet of supercooled liquid (Vali et al. 2015)] ranging from 3 to $250 \mathrm{~m}^{-3}$ (median $14 \mathrm{~m}^{-3}$ ) over the Southern Ocean (Bigg 1973). More recently, DeMott et al. (2015) compared number concentrations and surface site densities of aerosols observed in some marine environments with laboratory studies where generated sea spray was the only INP source. Their data suggest that marine INPs are distinctly less efficient than land-sourced INPs such that the ice nucleating ability of marine aerosol needs to be parameterized separately from terrestrial sources in atmospheric models. To understand the role of sea spray aerosol (SSA) in global INP populations, the abundance and characteristics of atmospheric marine INPs must be probed, and the physical and chemical mechanisms that regulate emissions of marine INPs need to be resolved.

Many studies have investigated SSA properties in both field (Fuentes et al. 2010; O'Dowd et al. 2004; Facchini et al. 2008) and laboratory studies (Prather et al. 2013; Collins et al. 2014). The size distribution and chemistry of ambient primary marine aerosols strongly depends on bulk seawater organic matter content (Fuentes et al. 2010; O'Dowd et al. 2004; Facchini et al. 2008) and wave breaking dynamics [i.e., surface wind speed, wave height, wind history, friction velocity, and viscosity (Gantt et al. 2011; Ovadnevaite et al. 2012)]. Studies have also shown that the sizes and compositions of laboratory-generated SSAs vary depending on the SSA generation technique (Prather et al. 2013; Collins et al. 2014). Although the properties of SSAs are dependent on the production mechanism and environment (which is variable around the globe), a few general chemical and physical characteristics of SSA are broadly consistent in previous studies, and they are summarized here to provide a background understanding of the materials found in SSA that are possible contributors to the INP population. The size distribution of SSA is considered to be lognormally distributed and centered at approximately 100 $200 \mathrm{~nm}$. Its chemical composition is dependent on particle size: supermicron SSA is dominated by sea salt particles, whereas submicron SSA contains more organic molecules (mostly exudates from phytoplankton and their breakdown products), gels (Orellana et al. 2011), and viruses, with the highest organic fraction found at the smallest sizes (O’Dowd et al. 2004; Facchini et al. 2008). Additionally, Prather et al. (2013) found that up to 17\% of laboratorygenerated supermicron SSA particles had chemical signatures indicative of microbes and their constituents [i.e., phosphate, organic nitrogen, and trace metals (see Guasco et al. 2014)] and Patterson et al. (2016) directly imaged biological material in SSA. Many of these constituents, including marine microbes (e.g., Bigg and Leck 2001; Junge and Swanson 2008; Knopf et al. 2011) and organic exudates (Mochida et al. 2002; Wilson et al. 2015) have been considered as potential INPs in SSA (Burrows et al. 2013). However, the identity of marine INPs remains uncertain, and few studies have directly monitored the constituents and how they contribute to the marine INP population.

The potential role of phytoplankton blooms in altering SSA chemical composition in a manner that increases INP production was proposed by Schnell and Vali (1976). Based on spatial correlations, they suggested that regions of oceanic upwelling, presumably regions of frequent phytoplankton blooms, corresponded to enhancements in INPs that were observed by Bigg (1973). Other field studies have presented evidence for a marine source of biological INPs (Schnell 1977, 1982; Rosinski et al. 1987), including aircraft measurements over the Arctic (Rogers et al. 2001) and filter collections on a ship voyage in the high Arctic (Bigg 1996). Schnell and Vali (1975) further demonstrated the potential for oceanic biological activity to generate INPs, wherein INPs measured in seawater samples collected following a phytoplankton bloom were significantly elevated above numbers observed in seawater samples collected elsewhere. More recently, Wilson et al. (2015) reported that the organic-rich sea surface microlayer (SML) collected from the Atlantic and Arctic Oceans contained ice nucleating material and that the organic exudates of phytoplankton (Thalassiosira pseudonana) were a probable contributor to marine INPs. Modeling studies have indicated that, by assuming a linear relationship between organic matter and ice nucleation activity, marine INPs could be significant contributors to the INP population in remote marine environments (Burrows et al. 2013; Wilson et al. 2015). However, studies have illustrated that climaterelevant properties (e.g., ice water path) of clouds in global climate model simulations are very sensitive to changes in ice nucleation efficiency of marine aerosol (Yun and Penner 2013), and thus these relationships must be evaluated with atmospheric aerosol measurements and analyses in many ocean environments and seasons. 
Two major challenges are faced when measuring atmospheric marine INPs. First, number concentrations of INPs associated with SSA approach the lower detection limits of many instruments (DeMott et al. 2015). Their low abundance requires methods that are able to collect large sample volumes, such as filter collections. However, this comes at the cost of high time resolution. The second major challenge is untangling marine INPs from the often significant or dominant presence of terrestrial INPs. For example, Mason et al. (2015) recently reported that INP concentrations were strongly correlated with fluorescent biological particles but were not correlated with tracers of marine aerosol and marine biological activity, indicating the biological particles emitted at their coastal sampling site were likely terrestrial. Laboratory studies accommodate these needs with large sampling volumes of nascent SSA, as demonstrated by DeMott et al. (2015), where INPs were monitored in SSA generated from seawater that was artificially altered with additions of biomass. They report that, indeed, INPs were more abundant in SSA generated from seawater containing more biomass (i.e., chlorophyll a), particularly at colder temperatures $\left(T<-26^{\circ} \mathrm{C}\right)$. However, they found that the relationship between INP number concentrations and bulk seawater chlorophyll a ( $\mathrm{Chl}$ a) was dependent on nucleation temperature, suggesting that multiple INP entities are present in SSA. Data reported by DeMott et al. (2015) suggest that the link between marine INPs and ocean biological activity is complex, and further evaluation of this link is needed in order to make estimates of atmospheric marine INPs.

In this study, we used a mesocosm approach, advanced from DeMott et al. (2015), to directly examine the hypothesis suggested four decades ago by Schnell and Vali (1976): emissions of INPs are enhanced as a result of biological activity. As part of the National Science Foundation Center for Aerosol Impacts on Climate and the Environment (CAICE), two mesocosm experiments were conducted in which nascent SSA was generated by both wave action and a close proxy method and sampled throughout the duration of the growth and degradation of a phytoplankton bloom. This study expands on previous laboratory studies of this hypothesized link (DeMott et al. 2015; Prather et al. 2013) by measuring INPs at temperatures ranging from $0^{\circ}$ to $-30^{\circ} \mathrm{C}$ and by describing biological activity with multiple parameters, including $\mathrm{Chl}$ a, counts of heterotrophic bacteria, and enzyme activity. Additionally, the evolution of aerosol composition was measured using online singleparticle mass spectrometry and offline microscopy techniques. Data presented here focus on the overall dynamics in INP abundance throughout the blooms and inferences regarding INP types that appear important based on temporal trends with biological activity and aerosol chemistry.

\section{Methods}

One of the main goals of the Investigation into Marine Particle Chemistry and Transfer Science (IMPACTS) and Marine Aerosol Reference Tank (MART) experiments was to provide a test bed for many hypotheses, including those related to hygroscopicity (Forestieri et al. 2016) and sea spray aerosol composition (Wang et al. 2015; Cochran et al. 2016). In this study, we use these previously published data to complement measurements of INPs during these two studies. Detailed descriptions are provided elsewhere for the mesocosm setup (Lee et al. 2015; Wang et al. 2015) and aerosol organic carbon (Cochran et al. 2016). Brief descriptions of these published methods are also described here, with detailed method descriptions of the unpublished data, including INP number concentrations, heterotrophic bacteria counts, bulk water enzyme activities, and aerosol size distributions.

\section{a. Mesocosm experimental details}

Two mesocosm experiments, both performed at the CAICE facilities at the University of California, San Diego, at Scripps Institution of Oceanography (SIO), are described in this study. The first was performed using a Marine Aerosol Reference Tank (Stokes et al. 2013). The MART is a $210-\mathrm{L}$ tank that produces SSA using a plunging sheet of water, repeated at 4-s intervals by recirculating a portion of the contained seawater. The aerosol sampling port for the MART study is located approximately $15 \mathrm{~cm}$ from the surface of the seawater. The second set of data is from the IMPACTS campaign (Wang et al. 2015) conducted at the SIO wave channel (dimensions: $33 \mathrm{~m}$ long, $0.6 \mathrm{~m}$ deep, and a volume of $13000 \mathrm{~L}$ ), which produces SSA via breaking waves (Prather et al. 2013; Collins et al. 2014). Aerosol measurements were made from the main sampling manifold used by all investigators, unless otherwise stated. This manifold drew air from approximately $20 \mathrm{~cm}$ above the surface of the seawater and approximately $1.2 \mathrm{~m}$ downstream of the breaking wave. During both studies, filtered air [high-efficiency particulate air (HEPA), $0.3-\mu \mathrm{m}$ pore size] was used to continuously purge the headspace and isolate the tank or wave flume from external particles. Particle counts were monitored in the headspace when the wave generation technique was off (i.e., no SSA production) to ensure leaks were not present during the studies. Aerosol concentrations $\left(D_{p}>500 \mathrm{~nm}\right)$ during a nonplunging period are shown in Fig. S2 (in the supplemental material). The aerosol produced by these two methods is considered nascent laboratory-generated 
SSA, and both methods produce similar aerosol size distributions (Prather et al. 2013) and size-resolved chemical mixing states (Collins et al. 2014). DeMott et al. (2015) have reported that INP number concentrations measured from these laboratory systems are generally similar to those observed in the ambient marine boundary layer when consideration is given to total particle emissions in the size range expected for SSA (i.e., ambient cases that did not include obvious pollution of nucleation-mode particles), indicating that these SSA generation techniques replicate the chemical composition and size distributions representative of ambient, remote marine air.

The two studies were performed during two periods; measurements were made from 6 to 27 January 2014 for the MART study and from 3 July to 9 Aug 2014 for the IMPACTS study. Experimental details have been previously described for the MART study [tank E in Lee et al. (2015)] and the IMPACTS study (Wang et al. 2015) and are repeated briefly here. The tanks, water pumps, buckets, and any other material that touched the seawater were sterilized ( $70 \%$ volume per volume ethanol, deionized (DI) water rinse and nascent seawater rinse). For both experiments, seawater was collected at the Ellen Browning Scripps Memorial Pier (at SIO in La Jolla, California, $32^{\circ} 52.00^{\prime} \mathrm{N}, 117^{\circ} 15.40^{\prime} \mathrm{W}$ ), located $275 \mathrm{~m}$ offshore. The seawater collection depths for the MART and IMPACTS studies were $0 \mathrm{~m}$ (i.e., sea surface) and approximately $4 \mathrm{~m}$ below the low tide level, respectively, because of the different collection methods required to collect the different volumes of water needed for the MART versus the wave flume. The influence of the different collection depths is expected to be minor compared to the seasonal differences because water above the ocean thermocline (upper 150-200 m) is well mixed. Seawater for the MART and IMPACTS studies was collected on 5 January and 3 July 2014, respectively. The phytoplankton blooms were prompted by the addition of nutrients $(\mathrm{f} / 2$ algae growth medium with sodium metasilicate; ProLine Pentair Aquatic Eco-Systems, Apopka, Florida), and tanks were equipped with $5700-\mathrm{K}$ full spectrum lights that provided sufficient light for the growth of phytoplankton (Brown and Richardson 1968; Lee et al. 2015). During the IMPACTS study, concentrations of Chl a in bulk seawater were monitored fluorometrically (Aquafluor, Turner Designs) several times a day as an indication of bloom growth. Additionally, in the MART experiment, extracted Chl a was measured with a fluorometer to assess the phytoplankton growth following the method of HolmHansen et al. (1965). To gather data to represent the initial INP number concentrations and aerosol composition, sampling was performed on the first day of each experiment (day 0) immediately following the nutrient addition (day 0 for MART and IMPACTS was 6 January 2014 and 3 July 2014, respectively). During the MART study, SSA production by plunging water commenced when $\mathrm{Chl}$ a started to increase exponentially, indicating the growth of phytoplankton. Plunging was not done during the phytoplankton growth phase because studies have suggested that the MART plunging waterfall mechanism may inhibit phytoplankton growth. The gentler wave breaking technique of the wave flume allowed SSA to be produced throughout the phytoplankton growth period of the IMPACTS experiment. During both experiments, perforated tygon tubing was used to aspirate the seawater with filtered air in between aerosol generation sampling periods. Sampling cycles, alternating between aerosol generation sampling periods and aspirating periods, were repeated every $2 \mathrm{~h}$ (MART) and $3 \mathrm{~h}$ (IMPACTS).

There were key differences between the two experiments that need to be considered while interpreting findings. Satellite and field observations of chlorophyll$a$ concentrations during phytoplankton blooms have reported values of up to $2-3 \mu \mathrm{g} \mathrm{L}^{-1}$ (Moore and Abbott 2000; Mongin et al. 2011). Thus, the MART experiment is more representative of a bloom with high phytoplankton biomass, with a peak of extracted Chl a concentration of $39 \mu \mathrm{g} \mathrm{L}^{-1}$, than the phytoplankton bloom observed during the IMPACTS study, with a peak Chl a concentration of approximately $5 \mu \mathrm{g} \mathrm{L}^{-1}$. Additionally, the scheduling of these experiments was constrained to availability of facilities, funding, and collaborative teams; thus, these experiments likely had differing microbial communities because of seawater samples that were collected during different seasons. Although these mesocosms are considered unconstrained, where the initial seawater contains an uncontrollable and unpredictable collection of biological microbes and species, they are both successions of naturally occurring microbes in the collected seawater, and the goal of this study was to determine if there was a relationship between INPs and various biological markers, including $\mathrm{Chl}$ a, total organic carbon (TOC), and abundance of heterotrophic bacteria.

\section{b. Ice nucleation measurement details}

Two techniques were used to monitor concentrations of immersion freezing INPs: The Colorado State University (CSU) continuous flow diffusion chamber (CFDC) and the CSU ice spectrometer (IS). The CFDC (Rogers et al. 2001; Petters et al. 2009) is an online instrument that measures the number concentration of condensationimmersion-mode INPs $\left(n_{\mathrm{INPs}}\right)$. The CFDC comprises two upright ice-coated cylindrical columns: a cold "inner wall" and a warmer "outer wall." A 1.2-cm gap exists between the two temperature-controlled walls, where a focused, laminar minor sample flow $\left(1.5 \mathrm{~L} \mathrm{~min}^{-1}\right.$, surrounded by 
8.5 $\mathrm{L} \mathrm{min}^{-1}$ of filtered sheath flow) is exposed to cloud relevant conditions. The temperature gradient between the walls creates conditions supersaturated with respect to ice and water. The CFDC was operated at supersaturations with respect to water $\left(\mathrm{SS}_{w}\right)$ of $3 \%-7.5 \%$ and sample lamina temperatures ranging from $-16^{\circ}$ to $-30^{\circ} \mathrm{C}$. The aerosol first encounters an impactor $\left(D_{50}=1.5 \mu \mathrm{m}\right.$ for this study) and is then dispersed between two sheath flows and enters the upper region of the chamber. As aerosol is drawn through the first two-thirds of the chamber, the nucleation/ growth region, particles activate as condensation nuclei, collect water, and grow in size. If a particle is active as an INP at the chamber conditions, an ice crystal will nucleate. The lower third of the column is a liquid evaporation region, where the two ice-coated walls are set to equivalent temperatures and the supersaturation is lowered to ice saturation (i.e., water subsaturation). At these conditions, the activated droplets evaporate while the ice crystals continue through the chamber unchanged, yielding a distribution of particles and hydrometeors that include evaporated droplets and haze particles $\left(D_{p}<1.5 \mu \mathrm{m}\right)$ and ice crystals $\left(D_{p}>\sim 4 \mu \mathrm{m}\right)$. Finally, an optical particle counter (OPC) is used to measure the resulting distribution.

The time resolution of the CFDC is $1 \mathrm{~Hz}$, and the number of ice crystals ranges from 0 to $2 \mathrm{~s}^{-1}$. As discussed by Richardson et al. (2007), frost from the chamber can gradually fall off throughout sampling. To account for this interference, we cycle between 3-5-min measurements of filtered air (filter periods) and 10-15-min of unfiltered sample air (sample periods). The frost counts measured during filter periods before and after the sample period were then interpolated over the sample period to estimate the background $n_{\text {INPs }}$. For this study, a threshold for the detection limit of statistically significant $n_{\text {INPs }}$ was defined as being two standard deviations above the background $n_{\text {INPs }}$ for time-integrated (10 min typically) sampling periods. This condition was met for all reported data in this paper. The statistically significant data are corrected by subtracting background counts from the counts measured during sampling. The median background $n_{\mathrm{INPs}}$ associated with data reported for these studies were less than $1 \mathrm{~L}^{-1}$ (Tables S1 and S2 in the supplemental material). Poisson counting statistics are used to describe the uncertainty in the $n_{\text {INPs }}$ (DeMott et al. 2015).

During the MART experiment, $2 \mathrm{~m}$ of $0.64-\mathrm{cm}$ inner diameter (ID) conductive tubing was used to connect the CFDC inlet to the MART sampling port. During the IMPACTS study, $3 \mathrm{~m}$ of $0.95-\mathrm{cm}$ ID stainless steel tubing was used to connect a flow of approximately 4.5 volumetric liters per minute (vlpm) from the community sampling manifold to a four-way splitter (TSI model 370800 ) and then another $0.5 \mathrm{~m}$ of $0.64-\mathrm{cm}$ ID conductive tubing was used to connect to the CFDC inlet. During both studies, inline silica gel dryers were used to dry the aerosol sufficiently for sampling. Losses of larger particles (here defined as particles with physical diameters $0.5<D_{p}<1.5 \mu \mathrm{m}$ ) in the sampling lines were estimated by taking the ratio of the number concentrations of larger particles measured by the CFDC OPC to that measured by the sizing suite (see section $2 \mathrm{c}$ ). This ratio was calculated using measurements of the SSA distribution for each sampling period. A particle loss calculator (von der Weiden et al. 2009) was used to estimate depositional losses in the sampling lines, which were found to be negligible $(<5 \%)$ for particles with diameters $0.04-1.4 \mu \mathrm{m}$. Losses of particles $\left(0.045<D_{p}<\right.$ $0.1 \mu \mathrm{m}$ ) due to diffusion in sampling lines are estimated to be less than $10 \%$ using a particle loss calculator (von der Weiden et al. 2009) and are negligible for particles larger than $D_{p}>0.1 \mu \mathrm{m}$ (Hinds 1999). Previous studies have investigated particle losses at sizes from 0.1 to $1.5 \mu \mathrm{m}$ within the CFDC, and these are limited to below $10 \%$ (Prenni et al. 2009). The INP number concentrations may be underestimated by up to $10 \%-20 \%$, which we consider insignificant for INP measurements.

The number of INPs emitted in the SSA in the wave flume, particularly at warmer temperatures, was low and oftentimes below the typical detection limit of the CFDC. Thus, during the IMPACTS study, an aerosol concentrator (MSP Corporation, model 4240) was used upstream of the CFDC, as is described in detail in a previous study by Tobo et al. (2013). The aerosol concentrator increases the detection limit of the CFDC by concentrating a sample flow from $\sim 250$ to $1.5 \mathrm{~L} \mathrm{~min}^{-1}$, thus enhancing concentrations of larger particles $\left(D_{p}>\right.$ $500 \mathrm{~nm}$ ) by a factor of up to 167 in theory (Romay et al. 2002). Because of preexisting damage to the aerosol concentrator, the concentrator was less effective, and thus the concentrator factor $(\mathrm{CF})$ was lower and variable (Tobo et al. 2013). In Tobo et al. (2013), the CF was determined based on the ratio of $n_{\mathrm{INPs}}$ measured on and off the aerosol concentrator. However, this method was not possible because of the low $n_{\text {INPs }}$ measured without the aerosol concentrator during the IMPACTS study. Thus, the CF was measured and specified each day by taking the ratio of $n_{500, \text { CFDC }}$ measured with and without the concentrator. Throughout the IMPACTS study, the $\mathrm{CF}$ ranged from 3.5 to $14.7\left(\mathrm{CF}_{\mathrm{avg}}=7.48 \pm 3.38\right.$, Table $\mathrm{S} 5$ in the supplemental material). In the few cases where $n_{\text {INP }}$ was successfully measured without the concentrator, the CF determined based on $n_{\text {INP }}$ was within a similar range $\left(\mathrm{CF}_{\text {avg,INPs }}=3.9 \pm 1.7\right)$. The measurement of $n_{\text {INPs }}$ with the concentrator was then divided by the measured CF. This estimation assumes that most the INPs are within the larger size range of the aerosol size 
distribution (i.e., large enough to be enhanced by the aerosol concentrator). However, the mode size of marine INPs has yet to be validated; thus, it is possible that this method may lead to an underestimation of INP number concentrations in the case that INPs are distributed in some manner across the SSA size distribution. This method would be most in error if there were a pronounced mode of INPs at sizes well below $500 \mathrm{~nm}$, which is not the case for terrestrial INPs or for INPs measured at coastal sites (Santachiara et al. 2009; DeMott et al. 2010; Mason et al. 2015). This sampling method, with the inherent assumption that a representative and quantifiable enhancement of INPs is achieved with the aerosol concentrator, advances the understanding of marine INPs by enabling the detection of low numbers of marine INPs with the CFDC.

The second ice nucleation detection method is an offline method, where particles are collected onto filters and then immersed into liquid for analysis with the IS (Hiranuma et al. 2015). Presterilized Nuclepore tracketched polycarbonate membrane filters $(47-\mathrm{mm}$ diameter, Whatman, GE Healthcare Life Sciences, Piscataway, New Jersey) with a pore size of 0.2 and $0.05 \mu \mathrm{m}$ were used in the MART and IMPACTS studies, respectively. A 3.0- $\mu \mathrm{m}$ pore-size filter was used as a clean backing for the filter, and both filters were held in an in-line aluminum filter holder (Pall Corporation, Cortland, New York). Average initial flow rates through the filters during the MART and IMPACTS studies were 4.4 and $2.4 \mathrm{~L} \mathrm{~min}^{-1}$, respectively. As discussed by DeMott et al. (2015), particle collection efficiencies should have exceeded $90 \%$ for all the particle sizes at the flow rates and the sampling setup of these studies. During the IMPACTS study, a 3-m sampling line was used for the IS filter collection (same as the CFDC), and particle losses associated with this long line were determined using a particle loss calculator (von der Weiden et al. 2009). Depositional losses were estimated to be negligible $(<5 \%)$ for particles with diameters up to $2 \mu \mathrm{m}$ and up to $30 \%$ for particles with diameter of $2.5 \mu \mathrm{m}$. Diffusional losses were also negligible $(<5 \%)$ for particles larger than $60 \mathrm{~nm}$. Thus, the IMPACTS IS filters are assumed to be capable of filtering particles of approximately less than $2.5 \mu \mathrm{m}$ in diameter $\left(\mathrm{PM}_{2.5}\right)$.

The precleaning protocol comprised soaking filters and dissembled filter holders (separately) in $10 \% \mathrm{H}_{2} \mathrm{O}_{2}$ for 10 and $60 \mathrm{~min}$, respectively, and three rinses with deionized water [18 megaohms $(\mathrm{m} \Omega)], 0.2-\mu \mathrm{m}$ pore filtered and, for filters, a further rinse in deionized water that had been passed through a $0.02-\mu \mathrm{m}$ pore Anotop syringe filter (Whatman)]. Excess water on filter holders was removed with a compressed air can duster. Filters and filter holders were then placed on aluminum in a clean space to dry. After sampling, the $0.2-0.05-\mu \mathrm{m}$ pore-size filters were removed from the filter holders with clean plastic forceps, placed in sterile petri dishes, sealed with parafilm, and stored frozen $\left(-20^{\circ} \mathrm{C}\right)$ until they were processed. To release collected particles, filters were immersed in $5 \mathrm{~mL}$ deionized, $0.02-\mu \mathrm{m}$ porefiltered water and shaken for $20 \mathrm{~min}$ (Rototorque, ColePalmer). Two, 96-well PCR trays ( $\mu$ Cycler; Life Science Products, Frederick, Colorado) are used to hold the aliquots of suspended material, where sets of 24-32 wells were used for each sample. The same aliquot volume was used for each sample well; the aliquot volume was either 80 or $50 \mu \mathrm{L}$ because of changes that occurred in our sampling protocol in efforts to save sampling volume. The PCR trays were then placed into the aluminum blocks in the IS. A chiller was used to cool the blocks from $0^{\circ}$ to $-25^{\circ} \mathrm{C}$ at $-0.33^{\circ} \mathrm{C} \mathrm{min}^{-1}$, and the number of wells frozen was counted every $0.5^{\circ}$ or $1^{\circ} \mathrm{C}$. Number concentrations of INPs per volume of liquid are determined as a function of temperature based on methods introduced by Vali (1971). This method assumes that freezing of nuclei occurs at the nuclei's activation temperatures and is independent of the rate of cooling. Additionally, the method assumes that the nuclei are evenly dispersed in the sample liquid. First, we determine the cumulative concentration spectrum that is defined by $-\ln (f) / V_{a}$ (Vali 1971), where $f$ is the fraction of unfrozen aliquots and $V_{a}$ is the aliquot volume. Computation of $n_{\text {INPs }}$ is then obtained from the total volume of DI used for rinsing $(5 \mathrm{~mL})$ and the volume of air collected. The volume of air collected onto the filter samples ranged from 270 to $431 \mathrm{~L}$ and 287 to $876 \mathrm{~L}$ during the MART and IMPACTS studies, respectively. Variations in air collection volumes were due to sampling scheduling. Blank filters were collected for both studies, and INP measurements of the rinse water from these were analyzed and subtracted from the counts made on collected samples prior to computation of volumetric concentrations in air. The number of INPs per blank filter can be found in Fig. S1 and Table S6 (in the supplemental material).

\section{c. Aerosol sizing measurements}

During both mesocosm experiments, aerosol size distributions were monitored with a scanning mobility particle sizer (SMPS; TSI model 3080, $0.014<D_{p}<$ $0.75 \mu \mathrm{m}$ ) and an aerodynamic particle sizer (APS; TSI model 3321, $0.54 \mu \mathrm{m}<D_{p}$ ). Aerosol diffusion driers were used to dry aerosol upstream of the SMPS and APS to $<20 \%$ relative humidity, and particles were assumed to be below their efflorescence relative humidity. The SMPS was operated with an aerosol flow rate of $0.3 \mathrm{~L} \mathrm{~min}^{-1}$ and sheath flow rate of $3 \mathrm{~L} \mathrm{~min}^{-1}$. The APS inlet has a total flow rate of $5 \mathrm{~L} \mathrm{~min}^{-1}$, consisting of a $1 \mathrm{~L} \mathrm{~min}^{-1}$ aerosol flow rate pulled through an inner nozzle surrounded by 
sheath flow $\left(4 \mathrm{~L} \mathrm{~min}^{-1}\right)$. Because of flow restrictions of the MART system, the APS configuration used a sampling inlet that pulled $1 \mathrm{~L} \mathrm{~min}^{-1}$ from the MART and $4 \mathrm{~L} \mathrm{~min}^{-1}$ filtered sheath flow from the room. Several corrections were applied to the APS data during the MART and IMPACTS studies: a size calibration was applied, the first three size bins of the APS were removed as a result of poor counting statistics, and particle density of SSA was assumed to be $1.8 \mathrm{~g} \mathrm{~cm}^{-3}$, based on Zelenyuk et al. (2007), to convert aerodynamic diameter to physical SSA diameter. The last 11 size bins were removed from the SMPS distributions because of poor counting statistics and the impactor $50 \%$ cutoff $\left(D_{50}=700 \mathrm{~nm}\right)$. These corrected SMPS and APS data were then merged and used as the aerosol size distribution.

In this study, the measured size distributions were integrated over three different size ranges to account for changes in INP counts due to changes in aerosol concentrations. The total number concentration of particles with $D_{p}<1.5 \mu \mathrm{m}\left(N_{\text {tot }}\right)$ calculated by summing the number concentrations of each bin from the merged size distribution, was used to normalize number concentrations determined from the CFDC (upper size limit of $1.5 \mu \mathrm{m})$. The total number concentration of particles with $0.5<D_{p}<1.5 \mu \mathrm{m}\left(N_{500 \mathrm{~nm}}\right)$ was calculated in the same manner as $N_{\text {tot }}$, where number concentrations of bins within this size range were added. Aerosol surface area was also calculated, assuming spherical shape, and the total surface area of particles $D_{p}<1.5 \mu \mathrm{m}\left(\mathrm{SA}_{\mathrm{tot}}\right)$ was used to calculate ice nucleation surface site density $\left(n_{s}\right)$.

\section{d. Detection of enzyme activity and microbes}

Seawater samples were collected daily, and enzyme activities were determined following the fluorogenic substrate method of Hoppe (1983). Briefly, L-Leucine7-amino-4-methyl-coumarin, 4-methyl-umbelliferone oleate, and 4-methyl-umbelliferone stearate were used to assess the protease, lipase-oleate, and lipase-stearate activity, respectively. Leucine-amino-methyl-coumerine (AMC) (LEU; protease) substrate and methyl-ubmelliferiloleate (MUF-OLE; lipase) and MUF-stearate (STE; lipase) substrates were added at saturation concentrations $(20 \mu \mathrm{M})$ in the seawater sample and incubated for $1 \mathrm{~h}$ in the dark at the in-situ temperature. Fluorescence measurements were taken at the beginning and at the end of the incubation to assess the hydrolysis rate with microliter plates (SpectraMax M3, Molecular Device) at $355 / 460 \mathrm{~nm}$ (excitation/emission). Once the substrate is enzymatically cleaved, released fluorophores, such as AMC and MUF, greatly increased their fluorescence signal, proportional to their hydrolysis. Calibration cures were measured with the free fluorophore to compute the hydrolysis rate as nanomoles per liter per hour.
Bacterial and viral abundances were measured in the bulk seawater and SSA according to Noble and Fuhrman (1998). The seawater samples were fixed with $0.02-\mu \mathrm{m}$ filtered formaldehyde solution (final concentration $2 \%$ ) and frozen until analysis. Once thawed, the samples were filtered onto a $0.02-\mu \mathrm{m}$ aluminum oxide filter $(0.02 \mu \mathrm{m}$ Whatman filters) and then stained with the asymmetrical cyanine dye SYBR Green I for $15 \mathrm{~min}$ at room temperature in the dark. The membranes were then mounted and immediately imaged using an inverted fluorescence microscope (wide-field Nikon TE2000-U) with a Plan Apochromat (VC 100x), 1.4 numerical aperture oil immersion objective (Nikon Instruments, Japan) and a CoolSNAP HQ charge-coupled device camera (Photometrics Inc.). Bacteria and viruses were counted in at least 20-30 fields of view at 490/528 nm (excitation/emission). Seawater, SML, and SSA collections were made every other day [note: aerosol measurements of heterotrophic bacteria (HB) began on day 10 during the MART experiment]. SSA was impinged into $0.2-\mu \mathrm{m}$ filtered autoclaved seawater in a 40 $\mathrm{mL}$ precombusted glass vial. Particles with $D_{p}>1 \mu \mathrm{m}$ are preferentially collected with the impinging method. The SML (upper $100 \mu \mathrm{m}$ of bulk seawater surface) was collected daily via the glass plate method (Cunliffe et al. 2013; Lee et al. 2015) for both MART and IMPACTS studies.

\section{e. Bulk aerosol total organic carbon measurements}

During the MART experiment, total suspended SSA was collected from the headspace of the MART on 47-mm quartz fiber filters (QFF) (Pall, Life Sciences) at a flow rate of $3.5 \mathrm{~L} \mathrm{~min}^{-1}$ using a custom-made single-stage aerosol sampler. The QFF were prebaked at $550^{\circ} \mathrm{C}$ for $18 \mathrm{~h}$ before sampling to remove contaminants, stored in aluminum foil-lined petri dishes sealed with Teflon tape, and kept at $-20^{\circ} \mathrm{C}$ before and after sample collection until analyzed. During IMPACTS, fine and coarse particulate matter $\left(\mathrm{PM}_{2.5}\right.$ and $\left.\mathrm{PM}_{10}\right)$ were collected onto QFF with a dichotomous sampler (Anderson Instruments, Inc.) as described in Cochran et al. (2016). For the MART and IMPACTS studies, the TOC content of SSA was quantified by a $1.00-\mathrm{cm}^{2}$ subsample of QFF using a thermal optical analyzer (Sunset Laboratories) following the National Institute for Occupational Safety and Health (NIOSH) method 5040 (Eller and Cassinelli 1999). The TOC concentration $\left(\mu \mathrm{g} \mathrm{m}^{-3}\right)$ was calculated using the total filter area and sampled air volume, which was calculated using total sampling time and average flow rate.

\section{Results}

\section{a. Overview of biological activity}

To describe biological activity of the bulk seawater during the MART and IMPACTS studies, Chl a concentrations, 
A) Ice nucleating particles
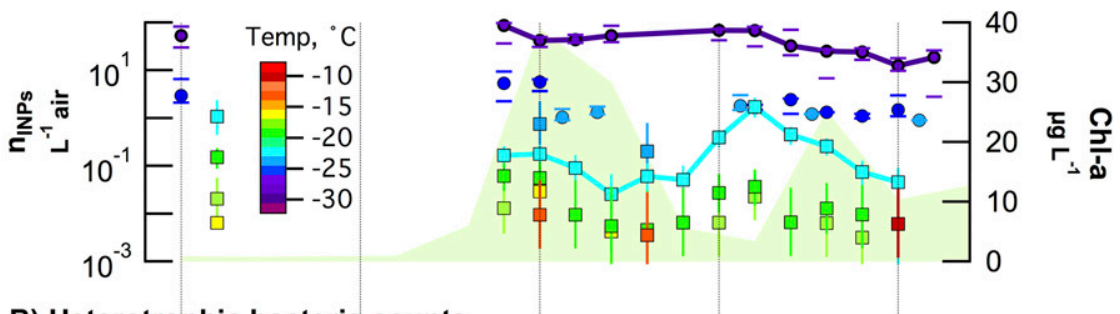

B) Heterotrophic bacteria counts

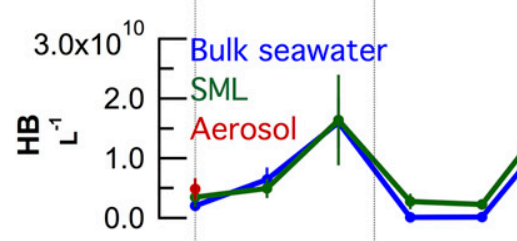

C) Total suspended aerosol

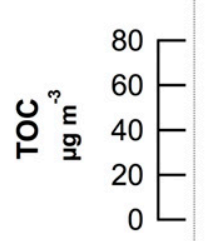

D) Bulk seawater enzyme activities

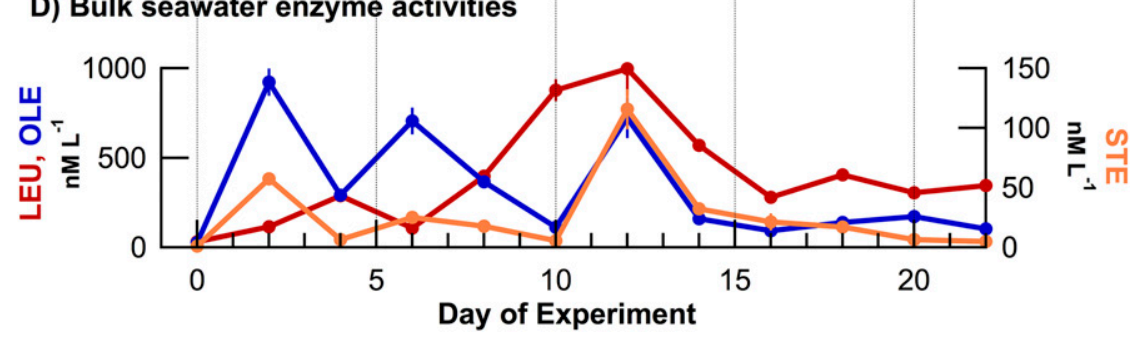

FIG. 1. (a) Timeline of INP number concentrations ( $n_{\text {INPs }}$; per liter of air; left axis) determined using the CSU CFDC (circle markers) and CSU IS (square markers) during the MART study. Colors indicate activation temperature denoted by the color scale. CFDC data are shown as median (filled circles) and the 5th and 95th percentiles (line markers below and above the circles, respectively). The IS data are shown as measured $n_{\mathrm{INPs}}$ and vertical bars represent the calculated $95 \%$ confidence interval. Chl a is shown as a green shaded area (right axis). (b) Microscopy counts of HB in the bulk seawater (blue), SML (green), and aerosol (red; right axis). (c) Mass concentrations of TOC in the total suspended aerosol. (d) Timelines of activity rates of LEU (protease, red), OLE (lipase, blue), and STE (lipase, orange) during the MART study. Day 0 is 6 Jan 2014.

counts of $\mathrm{HB}$, and enzyme activities are reported. During the MART experiment, an increase of phytoplankton (Chl a) began on day 8 and peaked on day $10\left(39 \mu \mathrm{g} \mathrm{L}^{-1}\right)$. A second bloom also occurred with its maximum in $\mathrm{Chl}$ a on day 18 (up to $25 \mu \mathrm{gL}^{-1}$ ), as shown in Fig. 1. Maxima in HB counts in bulk seawater were observed on day 4 and day 12 . The maximum in HB on day 4 was likely associated with changes in the initial phytoplankton and bacterial communities in the seawater caused by being in a different environment of the MART tank with spiked nutrients. The second HB peak (day 12) lagged the initial increase in Chl a (day 8 ) by 4 days and was likely associated with the increase in available organic material produced by the phytoplankton bloom. The number of HB in the SML and bulk seawater were similar at the beginning of the MART study; after day 12, the number of HB in the SML remained elevated while that in the bulk seawater decreased, suggesting that the SML was enriched with microbes compared to the bulk seawater. The transfer of these microbes to the aerosol phase is discussed in section $3 \mathrm{~b}$. The biological activity within mesocosms can also be interpreted via the dynamics of enzyme activity in the bulk seawater, as illustrated in Fig. 1d. It can be seen that the decrease in Chl a (days 10-14), indicating the demise of the 
phytoplankton bloom, was immediately followed by a peak in protease (LEU) activity on day 12 . The protease dynamics suggests an increase of proteins in the organic matter pool available for bacteria upon hydrolysis in order to satisfy their nitrogen requirements. Trends in lipase activity (i.e., enzymes that break down lipids) are also shown in Fig. 1d, where elevated lipase activity (OLE and STE), indicative of the presence of microbes possibly satisfying their carbon requirements, corresponded to periods of elevated bulk seawater $\mathrm{HB}$ counts, especially during the onset of the collapse of the primary bloom (day 12, immediately following the peak in $\mathrm{Chl}$ a).

As shown in Fig. 2a, the IMPACTS study contained lower levels of $\mathrm{Chl}$ a compared to the MART study. Chl a concentrations depict that two blooms also occurred during this study, with the first bloom of phytoplankton initiating around day 7 and maximizing on day 14 (approximately $4 \mu \mathrm{g} \mathrm{L}^{-1}$ ) and the second bloom initiating on day 17 and remaining elevated through days $21-25$. HB counts from the bulk seawater are shown in Fig. 2b, where peaks in HB abundance in the bulk water and SML coincided with the two blooms (day 12 and day 24) and lagged the commencement of the phytoplankton blooms (day 7 and day 17), similar to the MART experiment. The concentrations of $\mathrm{HB}$ in the bulk water associated with the second bloom were twice those observed during the first bloom. HB counts in the SML followed the dynamics of the HB in the bulk seawater more closely than that in the MART study. Furthermore, the enrichment of HB in the SML is not as apparent compared to the MART study. Protease activity dynamics follow the increases in $\mathrm{Chl}$ a and thus the phytoplankton bloom (Fig. 2d). Additionally, the lipase activities are highest during the second bloom, coinciding with the highest concentration of HB in the bulk water.

\section{b. Review of aerosol composition}

Here, we review previously published relevant, offline microscopy analyses and online single-particle chemistry to summarize the changes in aerosol composition during these phytoplankton blooms. Aerosol composition measurements during the MART experiment were previously published by Lee et al. (2015). The organic nitrogen marker ion $\left(\mathrm{CN}^{-}\right)$intensity observed by the aerosol time of flight mass spectrometer (ATOFMS on salt particles $\left(0.3<D_{p}<3 \mu \mathrm{m}\right)$, increased by a factor of 4 between day 0 and postbloom periods (day 13-22), indicating that the amount of nitrogen-containing organics associated with the sea salt particles (particles with ion spectra dominated by sodium and chlorine ion markers) increased through the duration of the bloom. Lee et al. (2015) also presented evidence from scanning electron microscopy (SEM) images of an increase in organic-like material coating the salt particles $\left(0.56<D_{p}<1 \mu \mathrm{m}\right)$ during the same period.
The presence of more organics on sea salt particles was correlated with an increase in dissolved organic carbon in the bulk water, which continued to increase and reached a maximum after the first peak in Chl a (Lee et al. 2015). As demonstrated in Fig. 1c, total organic carbon was detected in the total suspended sea spray aerosol, with some variability: it was not correlated with other biological indicators or the amount of organics measured with sea salt particles. The transfer of microbes into the aerosol phase during the MART study can be inferred from Fig. 1b, where HB number concentrations in the aerosol ranged from $2 \times 10^{3}$ to $1 \times 10^{4} \mathrm{HB} \mathrm{L}^{-1}$. Of note is the trend in aerosolized $\mathrm{HB}$, where a maximum was observed on day 18 and coincided with periods when the SML contained elevated concentrations of $\mathrm{HB}$ relative to the bulk seawater. Variability in the ratio of aerosolized $\mathrm{HB}$ and $\mathrm{HB}$ present in the SML may be due to variations in SML composition that lead to more favorable surface properties (e.g., changes in surface tension) for the emission of these microbes.

A detailed evaluation of the organic contribution to SSA during the IMPACTS study has been published by Wang et al. (2015). ATOFMS and Aerosol Mass Spectrometer (AMS; Aerodyne) results indicate two distinct types of organics in the SSA, including aliphatic-rich submicron organic and oxygen-rich supermicron organic species, were present. Because of their short lifetime and aliphatic character, Wang et al. (2015) reported that the aliphaticrich organic type was likely associated with labile species, most likely triacylglycerides. Furthermore, Raman microspectroscopy results indicate that long-chain fatty acids were the dominant contributor to the organic submicron $\left(0.56<D_{p}<1 \mu \mathrm{m}\right.$ ) aerosol (up to $70 \%$ ) (Wang et al. 2015). Aliphatic-rich submicron organic aerosol peaked on day 14 of the experiment, whereas the organic-rich supermicron organic type gradually increased throughout the study (Wang et al. 2015). Aerosolized HB were also evaluated via microscopy of collected aerosol, shown in Fig. $2 \mathrm{~b}$, with concentrations ranging from $5 \times 10^{4}$ to $2 \times$ $10^{5} \mathrm{HBL}^{-1}$ air, and were significantly lower than during the MART study. An increase in aerosolized HB (factor of 5) was observed on day 14, possibly associated with a shortlived shift in the SML properties, as previously mentioned.

\section{c. Trends in INP concentrations}

An unknown diversity of SSA constituents contributes to the overall marine INP population. One approach to explore these various INP types is to examine trends in INPs active in various temperature regimes versus trends in other biological and chemical markers. We define three additional terms for this purpose: $n_{\mathrm{INPs} \text {,cold }}$ refers to $n_{\mathrm{INPs}}$ measured below $-25^{\circ} \mathrm{C}, n_{\mathrm{INPs}, \text { mid }}$ refers to $n_{\mathrm{INPs}}$ active between $-25^{\circ}$ and $-15^{\circ} \mathrm{C}$, and $n_{\mathrm{INPs} \text {,warm }}$ refers to $n_{\mathrm{INPs}}$ measured at temperatures warmer than $-15^{\circ} \mathrm{C}$. To 
A) Ice nucleating particles

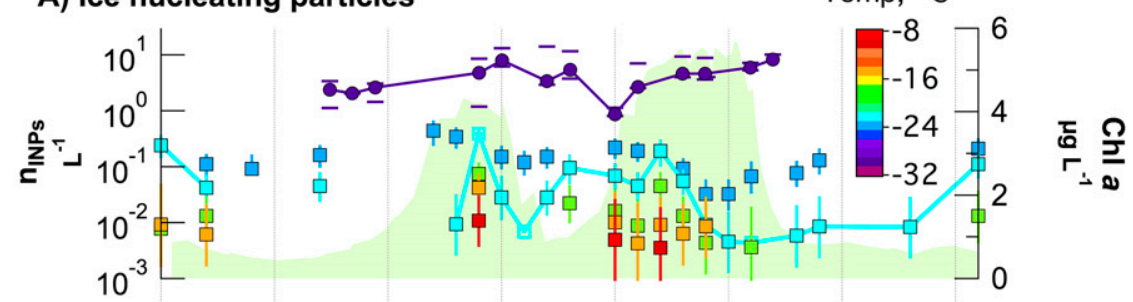

B) Heterotrophic bacteria counts

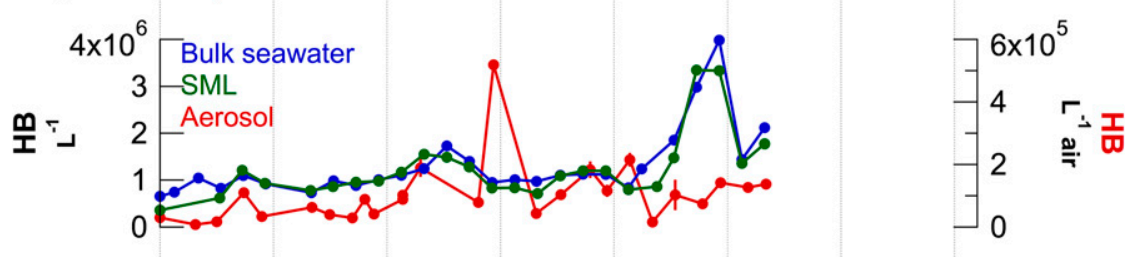

C) Total suspended aerosol TOC

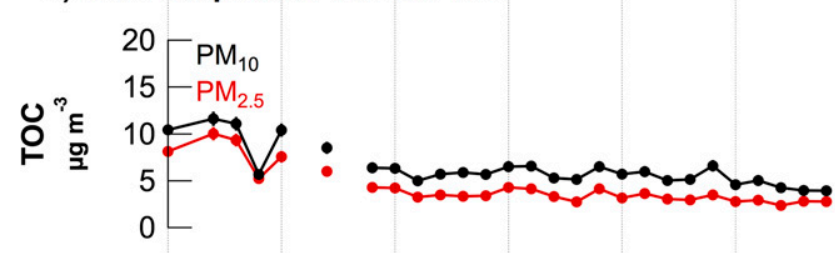

\section{D) Bulk seawater enzyme activities}

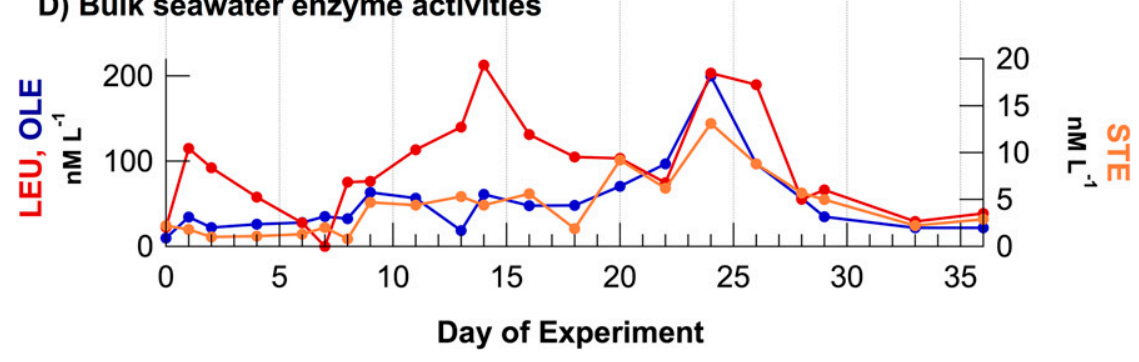

FIG. 2. As in Fig. 1, but for the IMPACTS experiment. Day 0 is 3 Jul 2015. TOC mass concentrations are shown for $\mathrm{PM}_{2.5}$ (red) and $\mathrm{PM}_{10}$ (black).

account for variations in aerosol number and distribution, we also report INPs normalized by total number concentration of particles $D_{p}<1.5 \mu \mathrm{m}\left(N_{\text {tot }}\right)$ and total surface area of particles $D_{p}<1.5 \mu \mathrm{m}\left(\mathrm{SA}_{\mathrm{tot}}\right)$, respectively.

Timelines of $n_{\mathrm{INPs}}$, measured from $T=-8^{\circ}$ to $-30^{\circ} \mathrm{C}$, and $\mathrm{Chl}$ a for the MART experiment are shown in Fig. 1a. Initially, INPs measured by the IS decreased between day 1 and day 9 . The aerosol size distribution between these two days shifted as a result of adjustments made to the water sheet. Thus, this decrease would either be due to changes in the aerosol generation (i.e., change in aerosol size distribution and number concentration) or changes in composition of the initial phytoplanktonic, bacterial, and viral communities during the growing stage of the bloom. However, the interpretation of this trend is limited because of the inability to measure from the MART system during the growing phase (see the methods). On day 10 , the warmest INP activity was observed by the IS at $-14^{\circ} \mathrm{C}$, and a modest peak in activity was observed at $-18^{\circ} \mathrm{C}$ (increase in $n_{\mathrm{INPs}, 18^{\circ} \mathrm{C}}$ by a factor of 2 ). A more significant peak in $n_{\mathrm{INPs} \text {,mid }}\left(n_{\mathrm{INPs}}\right.$ at $-22^{\circ} \mathrm{C}$ increased by a factor of 30) occurred on day 16, lagging the peak in Chl a by 4 days. In general, little variability in $n_{\text {INPs,cold }}$ was observed. These temporal trends at various temperatures are further illustrated in Fig. 3, where INP activity temperature spectra are shown for four focus periods. In Fig. 3a, the number fraction of INPs to total aerosol particles $\left(D_{p}<1.5 \mu \mathrm{m}\right)$ is shown as a function of temperature to normalize for any variability in aerosol number concentrations throughout the study. Variations in aerosol distributions are also accounted for in Fig. $3 \mathrm{~b}$, where $n_{\mathrm{INPs}}$ were normalized by total aerosol surface area $\left(D_{p}<1.5 \mu \mathrm{m}\right)$. These data confirm that the emissions of INPs given by either number fractions or 

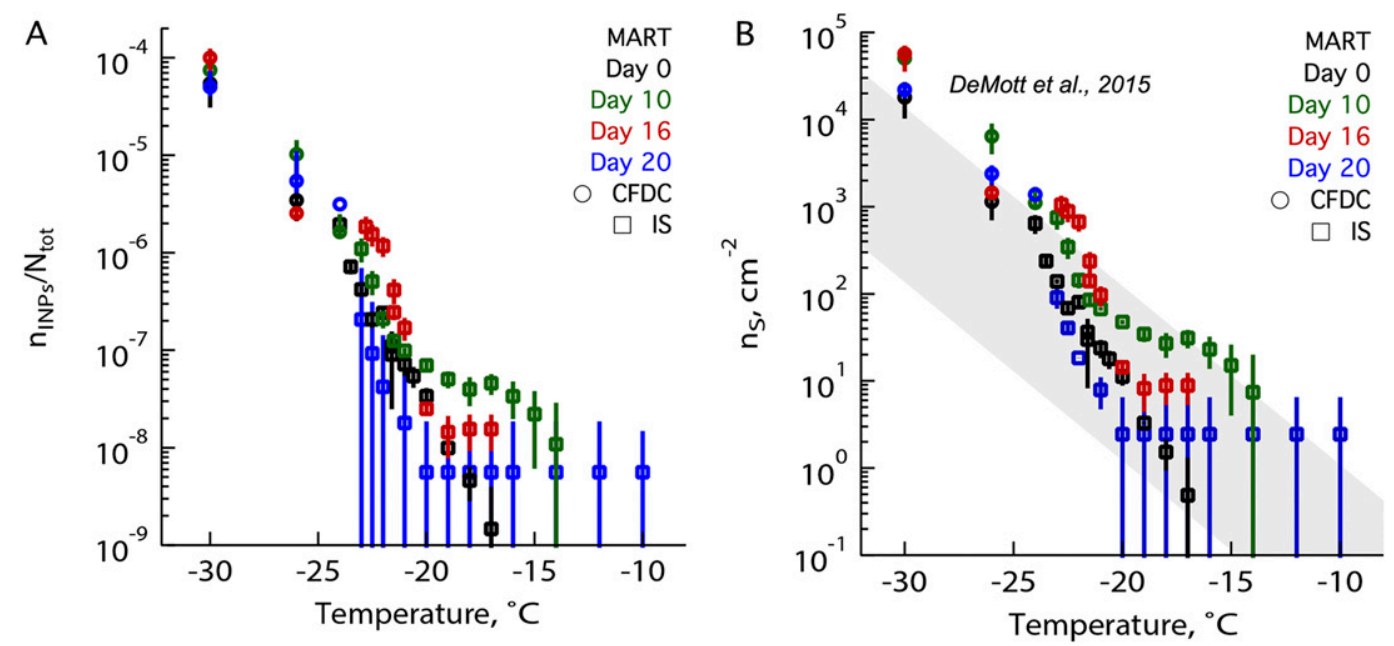

FIG. 3. Ice nucleation activity temperature spectra normalized by (a) total aerosol number concentrations and (b) total aerosol surface area (markers) for case study days of the MART study. Vertical bars show the propagated error for $n_{\mathrm{INP}}$ and aerosol measurements. Also shown in (b) is the range of nucleation site density values (gray shading) for marine aerosol reported by DeMott et al. (2015).

surface area from the MART before and after the bloom (days 0 and 20) were similar and that the aforementioned temporal dynamics of $n_{\mathrm{INPs} \text {,mid }}$ and $n_{\mathrm{INPs} \text {,warm }}$ during the interim period are independent of variations in aerosol production (i.e., total emissions and size distributions). These data are also compared to previous measurements of marine INPs in Fig. 3b, confirming that nucleation site density is within the range of values reported by DeMott et al. (2015).

For the IMPACTS study, timelines of $n_{\text {INPs }}$ at various temperatures $\left(-20^{\circ}\right.$ to $\left.-8^{\circ} \mathrm{C}\right)$ and $\mathrm{Chl}$ a concentrations are shown in Fig. 1a. Similar to the MART study, the most dynamic temperature regime of INPs captured throughout the duration of the blooms was $n_{\text {INPs,mid. The }}$ first peak in $n_{\text {INPs,mid }}$ occurred on day 14, with a sharp increase by a factor of 40 in $n_{\mathrm{INPs},-22^{\circ} \mathrm{C}}$ from day 13 to day 14. A second broader peak (days 17-23) in $n_{\mathrm{INPs}, \text { mid }}$ was observed, comprising an increase in $n_{\mathrm{INPs},-22^{\circ} \mathrm{C}}$ by over a factor of 10 and lagging the first $\mathrm{Chl}$ a peak by 4 days. On days 14,20 , and 22 , coincident with the first and second INP peaks, IN activity was observed at $-8^{\circ} \mathrm{C}$, the warmest temperature observed for IN activity in both studies. Contrasting with the MART study, $n_{\text {INPs,cold }}$ varied by an order of magnitude, with $n_{\mathrm{INPs},-30^{\circ} \mathrm{C}}$ reaching maxima on day 15 and day 26 . Figure 4 shows IN activity temperature spectra for focus days during the IMPACTS study, accounting for changes in aerosol generation as in Fig. 3 and revealing that, again, trends in $n_{\text {INPs,cold }}, n_{\text {INPs,mid }}$, and $n_{\text {INPs,warm }}$ were independent of particle emission variations and that the majority of these measurements fall within the range of previous measurements reported by DeMott et al. (2015).

\section{Discussion}

\section{a. Indirect evidence for the identity of marine ice nucleating particles}

Figures 1a and 2a illustrate that changes in $n_{\text {INPs }}$ were observed during both bloom experiments, that INP peaks were not directly related to $\mathrm{Chl}$ a concentrations, and that the response in $n_{\text {INPs }}$ across the three temperature categories was not uniform, supporting the expectation that the two populations of INPs indeed comprised diverse identities that expressed themselves at different points throughout the chronosequence of each phytoplankton bloom. Here, we aim to address the possible SSA constituents observed in the aerosol composition measurements and their correlation with INP emissions.

During the MART study, increases in organic aerosols detected by the ATOFMS and SEM (days 13-20) corresponded to periods of increased $n_{\text {INPs,mid }}$ emissions (peak $n_{\mathrm{INPs}, \mathrm{mid}}$ on day 16), suggesting that biomolecules, likely residing in the SML, were also transferred to the aerosol phase and represented strong potential contributors to the total INP population within the MART system. However, higher-resolution data, such as that obtained during the IMPACTS study, would have been advantageous to capture rapid perturbations in $n_{\text {INPs }}$ and organic aerosol. A potentially important SSA INP constituent is $\mathrm{HB}$, and these data indicate that elevated aerosolized HB (days 16-18) coincided with a multiday "breath" of $n_{\mathrm{INPs}, \text { mid }}$ observed after the bloom (days 14-19). This correlation may indicate the presence of bacteria that are IN active at lower temperatures than their terrestrial counterparts or that other microbes were also 

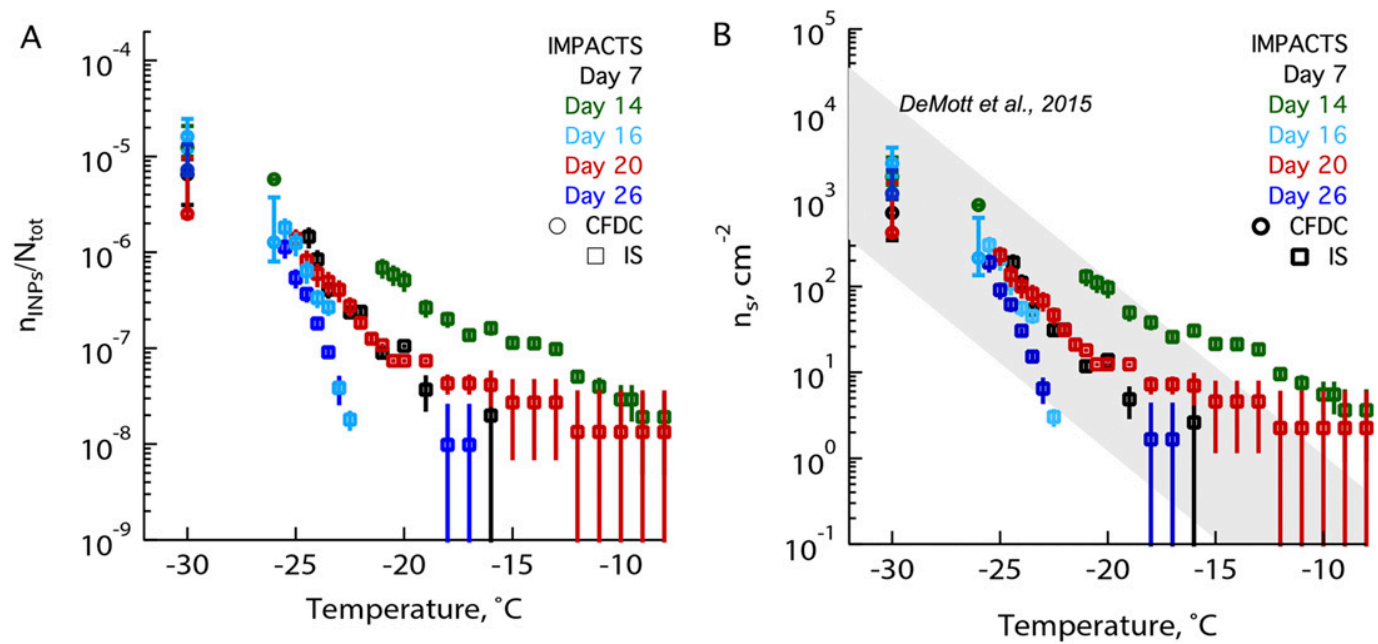

FIG. 4. As in Fig. 3, but for the IMPACTS study.

more enhanced in the aerosol phase on those days, such as diatoms, fragments of diatoms, or viruses. Evaluation of trends in enzyme activities within the bulk seawater can also elucidate contributions from biomolecules and microbes. For example, if a relationship between $n_{\mathrm{INPs}}$ and protease activity is observed, the growth of proteaseproducing HB is probably linked to the INP population. Similarly, a trend of $n_{\text {INPs }}$ with lipase activity would suggest that a portion of the INP population is linked to the presences of microbes that degrade lipids. Evaluation of enzyme activity revealed little indication of any correlations with $n_{\text {INPs }}$; however, an increase in protease enzyme activity (day 12, Fig. 1d) was coincident with a minimum in $n_{\text {INPs,mid }}$ (day 12), and vice versa on day 16 . Summarizing the MART study, measurements of HB and organic aerosol indicate that the most dynamic population of INPs, active between $-25^{\circ}$ and $-15^{\circ} \mathrm{C}$, may have been biomolecules or heterotrophic bacteria.

During the IMPACTS study, a strong relationship between submicron aliphatic-rich organics and INP emissions was observed on day 14 , where the first peaks in $n_{\text {INPs,warm }}$ and $n_{\text {INPs,mid }}$ were elevated coincident with a higher fractional contribution of the aliphatic-rich organics to the total $\mathrm{PM}_{1}$ measured by the AMS. By contrast, the oxygen-rich supermicron organic type gradually increased throughout the first bloom and leveled off, with no correlation with INP emissions. Although seemingly disconnected from abundances of $\mathrm{HB}$ in the bulk seawater and SML, days that had higher levels of aerosolized $\mathrm{HB}$ also tended to have the warmest temperature $\left(-8^{\circ} \mathrm{C}\right.$, day 14$)$ INPs. The contribution of both biomolecules and microbes to the INP population on day 14 is further supported by trends in enzyme activity; the peaks in $n_{\mathrm{INPs}, \text { mid }}$ and $n_{\mathrm{INPs} \text {,warm }}$ corresponded to a peak in protease activity, suggesting that protein-utilizing constituents (i.e., bacteria or diatoms) contributed to the INP population that was emitted on day 14 . The second peak in $n_{\mathrm{INPs}, \mathrm{mid}}$ (days 17-23) was not correlated with organic aerosol or aerosolized HB. Interestingly, in this episode, elevated protease and lipase activities (peaked on day 24) were associated with a decline in the second $n_{\mathrm{INPs} \text {,mid }}$ peak, suggesting that this INP population in this second peak may have also included protein-containing microbes and/or intact lipids. Also shown in Fig. 2 is a positive relationship of $n_{\text {INPs,cold }}$ $\left(r^{2}=0.706\right)$ with lipase enzyme activity, indicating that an increase in processed lipids, including fatty acids, may be important for INPs active at colder temperatures.

No evidence was found to support a direct relationship between Chl a or total organics and $n_{\mathrm{INPs}}$, as suggested previously (Prather et al. 2013). However, a complex relationship between INPs released in the aerosol and the microbiology occurring in the seawater was observed. In general, the MART and IMPACTS studies possessed similarities in the response of INP production to $\mathrm{Chl} \mathrm{a}$, in which $n_{\text {INPs,mid }}$ was found to increase approximately $3-4$ days after the collapse of the bloom. The increase in INPs was associated with the apparent degradation of phytoplankton exudates by bacterial enzymatic activity via the microbial loop. This trend scaled with the density of the bloom, where a 30 -fold increase was observed during the MART study and only a 13-fold increase was observed in the IMPACTS study. However, tremendous complexity is evident, where slight alterations in the SML, on time scales shorter than 1 day, facilitate higher releases of both aliphatic-like organic aerosol and HB, drastically increasing emissions of INPs active over a broad temperature range. Although these two laboratory experiments provided evidence to support future investigations on marine biomolecules and microbes as INPs, there could also be a benefit in future studies that investigate simpler 

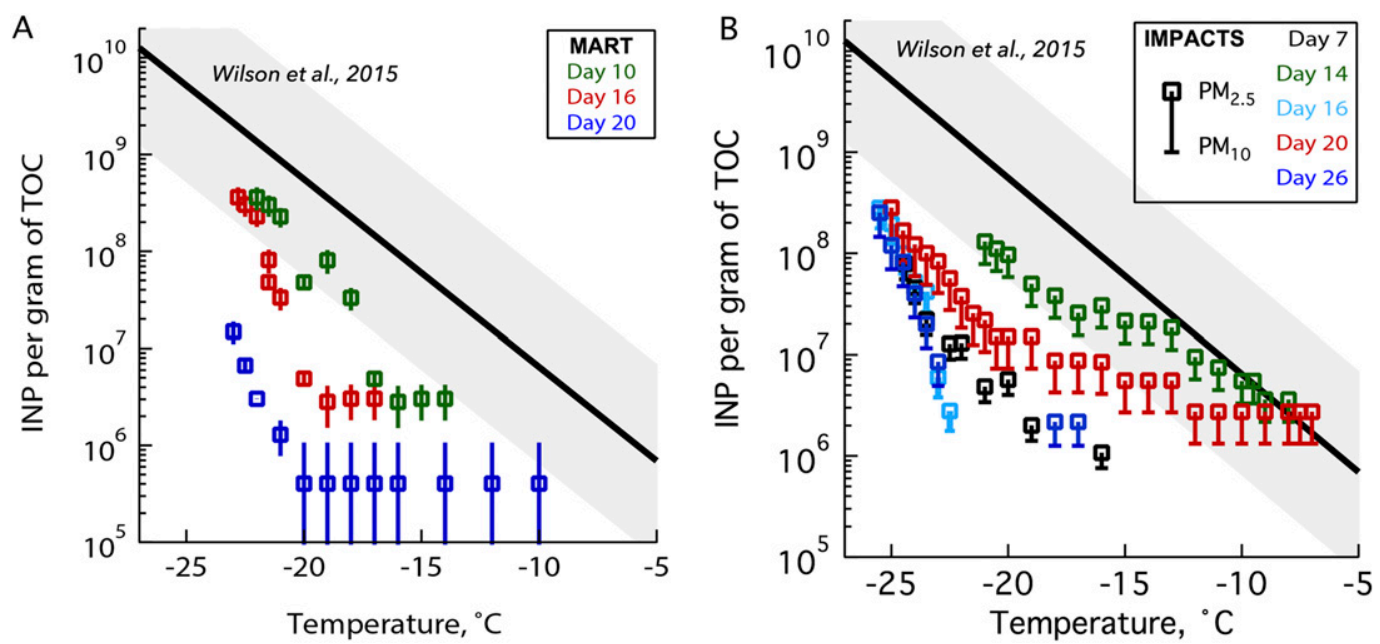

FIG. 5. (a) INP-to-TOC ratio of sea spray aerosol generated on focus days of the MART experiment determined using the ice spectrometer. Aerosol total suspended TOC data are not available for day 0 of the MART study. (b) As in (a), but during focus days of the IMPACTS study determined using the ice spectrometer. The INP-to-TOC ratio is estimated using $\mathrm{PM}_{2.5}$ (square markers) and $\mathrm{PM}_{10}$ (short horizontal line segments). In both (a) and (b), estimated INP-to-TOC ratios from Wilson et al. (2015) are shown (black line), and the shaded region outlines an order-of-magnitude spread above and below that parameterization.

systems in terms of the diversity of phytoplankton and microbial populations.

\section{b. Atmospheric implications}

Ultimately, comprehensive ambient marine INP measurements should be used to develop a parameterization to represent links between $n_{\mathrm{INPs}}$ and ocean biological activity in numerical models (DeMott et al. 2015). These data would need to probe diverse regions and scenarios to adequately represent the key aspects of hemispheric, latitudinal, and regional differences in microbial diversity, seasonal variability, and changes in INP activity associated with atmospheric processing of SSA, all of which are not represented during laboratory generation of SSA. This is clearly demonstrated by comparisons of CAICE laboratory studies to ambient measurements of aerosol size distributions, discussed by DeMott et al. (2015). Hence, the development of a marine INP parameterization is not addressed in this manuscript.

To put these findings into context with the current understanding of atmospheric marine INPs, we compare our results to the recent parameterization proposed and implemented by Wilson et al. (2015). In Wilson et al. (2015), SML measurements were used to determine a relationship between INPs and mass of total organic carbon within the SML. Their parameterization estimates the number of INPs present in the atmosphere based on two predictors: ambient temperature and mass of marine total organic aerosol. Accordingly, the number of INPs was assumed to be directly related to total organic carbon mass transferred into SSA (Wilson et al.
2015). TOC mass concentrations were measured for total suspended aerosol during the MART experiment (Fig. 1c) and were used to estimate INP-to-TOC ratios in the aerosol phase during the MART study, as shown in Fig. 5a. IMPACTS INP-to-TOC ratios were calculated with $\mathrm{PM}_{2.5}$ and $\mathrm{PM}_{10}$ TOC mass concentrations, and both values are used to provide a range of values for this study, shown in Fig. 5b. Unlike the MART study, where the IS filters were collected with minimal tubing, the IS filters collected during the IMPACTS study are likely more representative of $\mathrm{PM}_{2.5}$ (see the methods). This analysis is only applied to the IS filter collections because of the upper size limit of the CFDC (recall, $\left.D_{p}<1.5 \mu \mathrm{m}\right)$. While a few measurements fall within an order of magnitude of the Wilson et al. (2015) parameterization, all of which were made during periods of the highest $n_{\text {INPs }}$ concentrations, the majority of the data from this study are nearly two orders of magnitude lower than the results reported by Wilson et al. (2015).

If we keep to the assumption that INPs are proportional to total organic matter alone (i.e., organics are the only source of marine INPs), differences between our results and the predictions of Wilson et al. (2015) may be explained by the complex interplay between the seawater, SML, and aerosol phase. During the process of bubble bursting, the SML entrains bulk seawater, and the emitted aerosol becomes a mixture of some components in SML and those scavenged from seawater. Thus, the enrichment factor for organics from the ocean to the aerosol can range across orders of magnitude [1 to >5000; Burrows et al. (2013); Quinn et al. (2015); 
and references therein]. Results from these laboratory studies indicate that enrichment factors must be taken into account when estimating INP emissions. Additionally, recent studies have revealed that the amount of organics transferred into the SSA depends both on the aerosol production mechanism (Collins et al. 2014) and the types of organics in SSA. Studies have revealed that the transfer of organics is a selective process, whereby some certain organic compounds are preferentially transferred from the SML to SSA (Frossard et al. 2014; Cochran et al. 2016). That is to say, if organics are the main constituents of marine INPs, quantifying the distribution of ice nucleating organics among the emitted aerosol is likely an important feature needed to estimate INP number concentrations. Another important difference between these two studies was the origin of the seawater and hence the biological species present; the IN ability of organics in the MART study may have differed intrinsically from the material studied by Wilson et al. (2015).

However, results from the MART mesocosm experiment indicate that the number of suspended INPs were independent of, or not correlated with, total suspended organic carbon in SSA. In fact, based on the findings of this study, microbes and biomolecules appear to both be contributors to marine INP populations. Efforts to parameterize the connection between INP emissions and bulk seawater or SML biological activity will need to account for both of these constituents and their enrichment factors. An illustration of the complexity of the link between bulk water components and potential suspended INP components is demonstrated by the HB counts from the IMPACTS study (Figs. 1b, 2b), where the abundance of HB found in the aerosol phase was inconsistent with that observed in the bulk water and SML. This inconsistency exemplifies that the material released in SSA is not linearly related to that observed in the SML, and consideration is needed of both the bulk seawater and SML in the transfer of those constituents to the SSA. We thus conclude that much work remains in understanding the numerous factors that modulate INP number concentrations associated with SSA. These include detailed information on INP identity (types of microbes and biomolecules) and their enrichments in aerosol compared to seawater and SML, aerosol emission mechanisms, and regional diversity.

\section{Summary}

This study utilized the laboratory setting to isolate dynamic relationships between atmospheric INPs and seawater biological activity, described here by $\mathrm{Chl}$ a, TOC, abundances of microbes, and enzyme activity, throughout the duration of two phytoplankton blooms.
The data reported here demonstrate that links exist between marine biological processes and ice nucleation properties. During both phytoplankton blooms, $n_{\mathrm{INPs}}$ increased, typically at moderate temperatures $\left(T=-25^{\circ}\right.$ to $-15^{\circ} \mathrm{C}$ ), following the peak in bulk water $\mathrm{Chl}$ a (i.e., phytoplankton growth). INPs active at various temperatures, indicative of various ice nucleating entities, had unique dynamics associated with the phytoplankton bloom, suggesting that the marine INP population is diverse. INPs active at warm temperatures $\left(-8^{\circ} \mathrm{C}\right)$ were observed on days of enhanced aerosolized heterotrophic bacteria, suggesting that microbes contributed to warmtemperature marine INPs. Aliphatic-like, submicron organic aerosol was found to correspond to INPs active at moderate and cold temperatures, supported by singleparticle chemistry. Based on these findings, future studies should aim to make direct measurements of INP chemical and physical properties. These results further indicate that estimates of marine INPs require predictors that describe more than total organic mass transferred into SSA. Future studies are motivated to evaluate and quantify the contribution of marine INPs to marine boundary layer INP populations in diverse oceanic regions, particularly in potential future climate scenarios with less ice cover and increased biological activity, and should aim to quantify the importance of these changes (i.e., how does a 10-fold increase in $n_{\mathrm{INPs},-20^{\circ} \mathrm{C}}$ influence properties of a cloud?).

Acknowledgments. The authors thank the National Science Foundation Center for Aerosol Impacts on Climate and the Environment (CAICE) and the CAICE research teams and the SIO hydraulics laboratory staff for organizing and conducting phytoplankton bloom experiments. CAICE (CHE-1305427) is a National Science Foundation Center for Chemical Innovation.

\section{REFERENCES}

Bigg, E. K., 1973: Ice nucleus concentrations in remote areas. J. Atmos. Sci., 30, 1153-1157, doi:10.1175/1520-0469(1973)030<1153: INCIRA $>2.0 . \mathrm{CO} ; 2$.

- 1996: Ice forming nuclei in the high Arctic. Tellus, 48B, 223 233, doi:10.1034/j.1600-0889.1996.t01-1-00007.x.

- and C. Leck, 2001: Cloud-active particles over the central Arctic Ocean. J. Geophys. Res., 106, 32 155-32 166, doi:10.1029/ 1999JD901152.

Brown, T. E., and F. L. Richardson, 1968: The effect of growth environment on the physiology of algae: Light intensity. J. Phycol., 4, 38-54, doi:10.1111/j.1529-8817.1968.tb04675.x.

Burrows, S. M., C. Hoose, U. Pöschl, and M. G. Lawrence, 2013: Ice nuclei in marine air: Biogenic particles or dust? Atmos. Chem. Phys., 13, 245-267, doi:10.5194/acp-13-245-2013.

Cochran, R. E., and Coauthors, 2016: Analysis of organic anionic surfactants in fine and coarse fractions of freshly emitted sea spray aerosol. Environ. Sci. Technol., 50, 2477-2486, doi:10.1021/ acs.est.5b04053. 
Collins, D. B., and Coauthors, 2014: Direct aerosol chemical composition measurements to evaluate the physicochemical differences between controlled sea spray aerosol generation schemes. Atmos. Meas. Tech., 7, 3667-3683, doi:10.5194/ amt-7-3667-2014.

Cunliffe, M., and Coauthors, 2013: Sea surface microlayers: A unified physicochemical and biological perspective of the airocean interface. Prog. Oceanogr., 109, 104-116, doi:10.1016/ j.pocean.2012.08.004.

DeMott, P. J., and Coauthors, 2010: Predicting global atmospheric ice nuclei distributions and their impacts on climate. Proc. Natl. Acad. Sci. USA, 107, 11217-11222, doi:10.1073/pnas.0910818107.

—_ and Coauthors, 2015: Sea spray aerosol as a unique source of ice nucleating particles. Proc. Natl. Acad. Sci. USA, 113, $5797-$ 5803, doi:10.1073/pnas.1514034112.

Eller, P. M., and M. E. Cassinelli, 1999: Elemental carbon (diesel particulate): Method 5040. NIOSH Manual of Analytical Methods, National Institute for Occupational Safety and Health, 9 pp.

Facchini, M. C., and Coauthors, 2008: Primary submicron marine aerosol dominated by insoluble organic colloids and aggregates. Geophys. Res. Lett., 35, L17814, doi:10.1029/2008GL034210.

Forestieri, S. D., and Coauthors, 2016: Linking variations in sea spray aerosol particle hygroscopicity to composition during two microcosm experiments. Atmos. Chem. Phys., 16, 9003 9018, doi:10.5194/acp-16-9003-2016.

Frossard, A. A., L. M. Russell, S. M. Burrows, S. M. Elliott, T. S Bates, and P. K. Quinn, 2014: Sources and composition of submicron organic mass in marine aerosol particles. J. Geophys. Res. Atmos., 119, 12 977-13 003, doi:10.1002/2014JD021913.

Fuentes, E., H. Coe, D. Green, G. de Leeuw, and G. McFiggans, 2010: On the impacts of phytoplankton-derived organic matter on the properties of the primary marine aerosol-Part 1: Source fluxes. Atmos. Chem. Phys., 10, 9295-9317, doi:10.5194/ acp-10-9295-2010.

Gantt, B., N. Meskhidze, M. C. Facchini, M. Rinaldi, D. Ceburnis, and C. D. O'Dowd, 2011: Wind speed dependent size-resolved parameterization for the organic mass fraction of sea spray aerosol. Atmos. Chem. Phys., 11, 8777-8790, doi:10.5194/ acp-11-8777-2011.

Guasco, T. L., and Coauthors, 2014: Transition metal associations with primary biological particles in sea spray aerosol generated in a wave channel. Environ. Sci. Technol., 48, 1324-1333, doi:10.1021/es403203d.

Hinds, W. C., 1999: Aerosol Technology: Properties, Behavior, and Measurement of Airborne Particles. 2nd ed. Wiley, 504 pp.

Hiranuma, N., and Coauthors, 2015: A comprehensive laboratory study on the immersion freezing behavior of illite NX particles: A comparison of 17 ice nucleation measurement techniques. Atmos. Chem. Phys., 15, 2489-2518, doi:10.5194/acp-15-2489-2015.

Holm-Hansen, O., C. J. Lorenzen, R. W. Holmes, and J. D. H. Strickland, 1965: Fluorometric determination of chlorophyll. J. Cons. Int. Explor. Mer, 30, 3-15, doi:10.1093/icesjms/30.1.3.

Hoppe, H. G., 1983: Significance of exoenzymatic activities in the ecology of brackish water: Measurements by means of methylumbelliferyl-substrates. Mar. Ecol. Prog. Ser., 11, 299308, doi:10.3354/meps011299.

Junge, K., and B. D. Swanson, 2008: High-resolution ice nucleation spectra of sea-ice bacteria: Implications for cloud formation and life in frozen environments. Biogeosciences, 5, 865-873, doi:10.5194/bg-5-865-2008.

Knopf, D. A., P. A. Alpert, B. Wang, and J. Y. Aller, 2011: Stimulation of ice nucleation by marine diatoms. Nat. Geosci., $\mathbf{4}$, 88-90, doi:10.1038/ngeo1037.
Komurcu, M., and Coauthors, 2014: Intercomparison of the cloud water phase among global climate models. J. Geophys. Res. Atmos., 119, 3372-3400, doi:10.1002/2013JD021119.

Korolev, A., 2007: Limitations of the Wegener-Bergeron-Findeisen mechanism in the evolution of mixed-phase clouds. J. Atmos. Sci., 64, 3372-3375, doi:10.1175/JAS4035.1.

Lee, C., and Coauthors, 2015: Advancing model systems for fundamental laboratory studies of sea spray aerosol using the microbial loop. J. Phys. Chem., 119A, 8860-8870, doi:10.1021/ acs.jpca.5b03488.

Mason, R. H., and Coauthors, 2015: Ice nucleating particles at a coastal marine boundary layer site: Correlations with aerosol type and meteorological conditions. Atmos. Chem. Phys., 15, 12 547-12 566, doi:10.5194/acp-15-12547-2015.

McCoy, D. T., D. L. Hartmann, M. D. Zelinka, P. Ceppi, and D. P. Grosvenor, 2015: Mixed-phase cloud physics and Southern Ocean cloud feedback in climatemodels. J. Geophys. Res. Atmos., 120, 9539-9554, doi:10.1002/2015JD023603.

Mochida, M., Y. Kitamori, K. Kawamura, Y. Nojiri, and K. Suzuki, 2002: Fatty acids in the marine atmosphere: Factors governing their concentrations and evaluation of organic films on sea-salt particles. J. Geophys. Res., 107, 4325, doi:10.1029/2001JD001278.

Mongin, M., R. Matear, and M. Chamberlain, 2011: Seasonal and spatial variability of remotely sensed chlorophyll and physical fields in the SAZ-Sense region. Deep-Sea Res. II, 58, 20822093, doi:10.1016/j.dsr2.2011.06.002.

Moore, J. K., and M. R. Abbott, 2000: Phytoplankton chlorophyll distributions and primary production in the Southern Ocean. J. Geophys. Res., 105, 28 709-28 722, doi:10.1029/1999JC000043.

Noble, R. T., and J. A. Fuhrman, 1998: Use of SYBR Green I for rapid epifluorescence counts of marine viruses and bacteria. Aquat. Microb. Ecol., 14, 113-118, doi:10.3354/ame014113.

O'Dowd, C. D., and Coauthors, 2004: Biogenically driven organic contributions to marine aerosol. Nature, 431, 676-680, doi:10.1038/ nature02959.

Orellana, M. V., P. A. Matrai, C. Leck, C. D. Rauschenberg, A. M. Lee, and E. Coz, 2011: Marine microgels as a source of cloud condensation nuclei in the high Arctic. Proc. Natl. Acad. Sci. USA, 108, 13 612-13 617, doi:10.1073/pnas.1102457108.

Ovadnevaite, J., D. Ceburnis, M. Canagaratna, H. Berresheim, J. Bialek, F. Martucci, D. R. Worsnop, and C. O'Dowd, 2012: On the effect of wind speed on submicron sea salt mass concentrations and source fluxes. J. Geophys. Res., 117, D16201, doi:10.1029/2011JD017379.

Patterson, J. P., and Coauthors, 2016: Sea spray aerosol structure and composition using cryogenic transmission electron microscopy. ACS Cent. Sci., 2, 40-47, doi:10.1021/acscentsci.5b00344.

Petters, M. D., and Coauthors, 2009: Ice nuclei emissions from biomass burning. J. Geophys. Res., 114, D07209, doi:10.1029/ 2008JD011532.

Prather, K. A., and Coauthors, 2013: Bringing the ocean into the laboratory to probe the chemical complexity of sea spray aerosol. Proc. Natl. Acad. Sci. USA, 110, 7550-7555, doi:10.1073/pnas.1300262110.

Prenni, A. J., P. J. Demott, D. C. Rogers, S. M. Kreidenweis, G. M. Mcfarquhar, G. Zhang, and M. R. Poellot, 2009: Ice nuclei characteristics from M-PACE and their relation to ice formation in clouds. Tellus, 61B, 436-448, doi:10.1111/j.1600-0889.2009.00415.x.

Pruppacher, H. R., and J. D. Klett, 1997: Microphysics of Clouds and Precipitation. 2nd ed. Atmospheric and Oceanographic Services Library, Vol. 18, Springer, 954 pp.

Quinn, P. K., D. B. Collins, V. H. Grassian, K. A. Prather, and T. S. Bates, 2015: Chemistry and related properties of freshly emitted sea spray aerosol. Chem. Rev., 115, 4383-4399, doi:10.1021/cr500713g. 
Richardson, M. S., and Coauthors, 2007: Measurements of heterogeneous ice nuclei in the western United States in springtime and their relation to aerosol characteristics. J. Geophys. Res., 112, D02209, doi:10.1029/2006JD007500.

Rogers, D. C., P. J. DeMott, S. M. Kreidenweis, and Y. Chen, 1998: Measurements of ice nucleating aerosols during SUCCESS. Geophys. Res. Lett., 25, 1383-1386, doi:10.1029/97GL03478.

- — - — , and —, 2001: A continuous-flow diffusion cham-
ber for airborne measurements of ice nuclei. J. Atmos. Oceanic Technol., 18, 725-741, doi:10.1175/1520-0426(2001)018<0725: ACFDCF $>2.0 . \mathrm{CO} ; 2$.

Romay, F. J., D. L. Roberts, V. A. Marple, B. Y. H. Liu, and B. A. Olson, 2002: A high-performance aerosol concentrator for biological agent detection. Aerosol Sci. Technol., 36, 217-226, doi:10.1080/027868202753504074.

Rosinski, J., P. L. Haagenson, C. T. Nagamoto, and F. Parungo, 1987: Nature of ice-forming nuclei in marine air masses. J. Aerosol Sci., 18, 291-309, doi:10.1016/0021-8502(87)90024-3.

Santachiara, G., L. Di Matteo, F. Prodi, and F. Belosi, 2009: Atmospheric particles acting as ice forming nuclei in different size ranges. Atmos. Res., 96, 266-272, doi:10.1016/j.atmosres.2009.08.004.

Schnell, R. C., 1977: Ice nuclei in seawater, fog water and marine air off the coast of Nova Scotia: Summer, 1975. J. Atmos. Sci., 34, 12991305, doi:10.1175/1520-0469(1977)034<1299:INISFW>2.0.CO;2. 1982: Airborne ice nucleus measurements around the Hawaiian Islands. J. Geophys. Res., 87, 8886-8890, doi:10.1029/ JC087iC11p08886.

— , and G. Vali, 1975: Freezing nuclei in marine waters. Tellus, 27A, 321-323, doi:10.1111/j.2153-3490.1975.tb01682.x. , and - 1976: Biogenic ice nuclei: Part I. Terrestrial and marine sources. J. Atmos. Sci., 33, 1554-1564, doi:10.1175/ 1520-0469(1976)033<1554:BINPIT>2.0.CO;2.

Stokes, M. D., G. B. Deane, K. Prather, T. H. Bertram, M. J. Ruppel, O. S. Ryder, J. M. Brady, and D. Zhao, 2013: A Marine Aerosol
Reference Tank system as a breaking wave analogue for the production of foam and sea-spray aerosols. Atmos. Meas. Tech., 6, 1085-1094, doi:10.5194/amt-6-1085-2013.

Tobo, Y., and Coauthors, 2013: Biological aerosol particles as a key determinant of ice nuclei populations in a forest ecosystem. J. Geophys. Res. Atmos., 118, 10100-10110, doi:10.1002/ jgrd.50801.

Vali, G., 1971: Quantitative evaluation of experimental results on the heterogeneous freezing nucleation of supercooled liquids. J. Atmos. Sci., 28, 402-409, doi:10.1175/1520-0469(1971)028<0402: QEOERA $>2.0 . \mathrm{CO} ; 2$.

—- P. J. DeMott, O. Möhler and T. F. Whale, 2015: Technical Note: A proposal for ice nucleation terminology. Atmos. Chem. Phys., 15, $10263-10270$, doi:10.5194/ acp-15-10263-2015.

von der Weiden, S. L., F. Drewnick, and S. Borrmann, 2009: Particle loss calculator-A new software tool for the assessment of the performance of aerosol inlet systems. Atmos. Meas. Tech., 2, 479-494, doi:10.5194/amt-2-479-2009.

Wang, X., and Coauthors, 2015: Microbial control of sea spray aerosol composition: A tale of two blooms. ACS Cent. Sci., $\mathbf{1}$, 124-131, doi:10.1021/acscentsci.5b00148.

Wilson, T. W., and Coauthors, 2015: A marine biogenic source of atmospheric ice-nucleating particles. Nature, 525, 234-238, doi:10.1038/nature14986.

Yun, Y., and J. E. Penner, 2013: An evaluation of the potential radiative forcing and climatic impact of marine organic aerosols as heterogeneous ice nuclei. Geophys. Res. Lett., 40, 41214126, doi:10.1002/grl.50794.

Zelenyuk, A., D. Imre, L. A. Cuadra-Rodriguez, and B. Ellison, 2007: Measurements and interpretation of the effect of a soluble organic surfactant on the density, shape and water uptake of hygroscopic particles. J. Aerosol Sci., 38, 903-923, doi:10.1016/ j.jaerosci.2007.06.006. 